\title{
Characterization, pathogenicity and anastomosis groups of Rhizoctonia solani from watermelon
}

\author{
Fábio Sanchez da Cunha, Antonio Elton da Silva Costa, Kecya Mayara de Araújo Galvão, \\ Alexandre Sandri Capucho, Francine Hiromi Ishikawa*
}

Federal University of the São Francisco Valley, Petrolina, Brazil

*Corresponding author, e-mail: francine.hiromi@univasf.edu.br

\begin{abstract}
The objective of this study was to characterize the morphological and pathogenic variation of Rhizoctonia solani isolates as well as to determine mycelial compatibility and hyphal fusion. The R. solani isolates CMM1053, CMM2967, CMM1052, CMM2983, CMM2971 and CMM3890 from watermelon were used. The determination of aggressiveness was evaluated using the six isolates inoculated in the Crimson Sweet susceptible cultivar in a completely randomized design (CRD) with five replicates, the sample unit consisting of one plant. The experiment of mycelial growth rate was installed in the factorial scheme, 6 isolates $\times 3$ culture media, using the following culture media Nutrient Agar, PDA and PSA, and a total of 5 replicates. The color characterization and sclerotia formation was performed 15 days after the fungal inoculation in each culture medium. For the characterization of vegetative compatibility and occurrence of hyphal fusion, the experiments were performed in CDR with three and two replicates, respectively. CMM1053 and CMM1052 isolates were the most aggressive; however, they were statistically different only from CMM2967 isolate. The PSA medium was the most promising for the mycelial growth. It was possible to observe that there was variability in the colonies color, being higher in the Nutrient Agar medium. Based on evaluations of vegetative compatibility and hyphal fusion, the six isolates belong to the same anastomosis group.
\end{abstract}

Keywords: Citrullus lanatus, damping-off, mycelial growth, plant breeding, vegetative compatibility

\section{Introduction}

The Watermelon, Citrullus lanatus, is a crop that has China as world's largest producer and Brazil occupies the sixth place among vegetable crops produced (FAO, 2015). The production may be affected by pathogen attack, and among them we can mention the fungus Rhizoctonia solani causal agent of damping-off or root rot of watermelon (Mirmajlessi et al., 2012).

Watermelon plants infected by $R$. solani present symptoms of seed rot, seedling death, stem cancer, root and fruit rot causing plant death and reduction in productivity (Aiello et al., 2012). R. solani is cosmopolitan and its identification is based on its morphology and molecular methods (Sneh et al., 1996). Its classification is based on anastomosis groups, which is defined as the somatic, or vegetative, manifestation of incompatibility between hyphae of different isolates of R.solani (Sneh et al., 1996). However, classification in anastomosis groups does not always correspond to the grouping of fungi that have the same aggressiveness, colony morphology, physiological characteristics and molecular methods (Das et al., 2014; Sneh et al., 1996). The fungus is polyphagous and according to Lakshman et al. (2008) presents 190 different host species. The fungus can live in the 
soil saprophytic way and can form resistance structures called sclerotia (Sneh et al., 1996). Such structures can provide viability of $10 \%$ to $40 \%$ after 18 months in soil (Ritchie et al., 2012). The most efficient method of controlling the disease is through genetic control, since there are no registered products for chemical control of this disease in Brazil.

For development of cultivars resistant to damping-off is necessary to obtain and characterize both, watermelon accessions and pathogen isolates. In nature, some of Rhizoctonia solani isolates have considerable variability in the morphology, physiology and its aggressiveness (Sherwood, 1970; Mikhail et al., 2010; Fiers et al., 2011). Erper et al. (2016) shows strains of Rhizoctonia solani isolated from winter squash (Cucurbita maxima) have variability in growth and color when grown on PDA (Potato Dextrose Agar). Moreover aggressiveness of the fungus between different anastomosis groups may also vary (Erper et al., 2016; Mathew et al., 2012; Oliveira et al., 2014).

The objective of this work was to characterize the morphological and pathogenic variation of Rhizoctonia solani strains obtained from watermelon, as to determine the vegetative compatibility and anastomosis of hyphae.

\section{Material and Methods}

The experiments were conducted in the Plant Pathology Laboratory and the greenhouse of UNIVASF in Petrolina, PE, Brazil. Six isolates of Rhizoctonia solani were obtained from the Phytopathogenic Fungal Culture Collection "Prof. Maria Menezes "- CMM, from Universidade Federal Rural de Pernambuco (Table 1). All the isolates were preserved in rice and had their pathogenicity restored by inoculation in watermelon.

Table 1. Description of Rhizoctonia solani isolates used in this study

\begin{tabular}{lccc}
\hline Isolate & Year & County - State & Host \\
\hline CMM1053 & 2006 & Quixeré- CE & Watermelon \\
CMM2967 & 2007 & Mossoró- RN & Watermelon \\
CMM1052 & 2006 & Quixeré- CE & Watermelon \\
CMM2983 & 2007 & Mossoró- RN & Watermelon \\
CMM2971 & 2007 & Baraúna- RN & Watermelon \\
CMM3890 & 2006 & Gama- DF & Watermelon \\
\hline
\end{tabular}

Aggressiveness of $R$. solani isolates

Aggressiveness was determined by inoculation of Rhizoctonia solani isolates on commercial cultivar Crimson sweet that is susceptible to disease. The design was a completely randomized with six isolates and five replicates plus control (without inoculation). The inoculum of each isolate was prepared independently in Erlenmeyer flasks of $250 \mathrm{ml}$. For this, $50 \mathrm{~g}$ of parboiled rice and $30 \mathrm{ml}$ of distilled water were autoclaved $\left(120^{\circ} \mathrm{C}, 15 \mathrm{~min}, 1 \mathrm{~atm}\right)$. From each isolate, growth in Potato Dextrose Agar (PDA) during five days at $25^{\circ} \mathrm{C}$, were removed three mycelium disc with a diameter of $3 \mathrm{~mm}$ to add per flask. After incubation at room temperature for a period of 7 days, all rice grains were colonized by the fungus was used as inoculum.

For sowing, $80 \mathrm{ml}$ disposable cups containing commercial substrate Topstrato ${ }^{\circledR}$ were used. The seeds were previously disinfected in $1 \%$ sodium hypochlorite for 30 seconds and washed in distilled water. When the seedlings presented the first pair of true leaves was performed inoculation with two grains of rice colonized by each isolate of pathogen. This procedure was carried out by packing the colonized rice grains near the hypocotyl of the seedlings and later covering the rice with the substrate.

For evaluations seven days after inoculation, it was used the scale proposed by Noronha et al. (1995) that has the following scores: 0 = no symptoms; 1 = hypocotyl with small lesions; 2 = hypocotyl with large lesions, but without constriction; 3 = hypocotyl totally constricted and showing damping-off; 4 = non-germinated seeds and / or seedlings not emerged. The Ducan means test was applied and the isolates with the highest mean values were considered the most aggressive.

After evaluation, two replicates of each treatment was carried out to laboratory 
to re-isolation of the pathogen from tissues with symptoms, aiming to closing of Koch's postulates. Observations of pathogen structures were also performed under a microscope.

Evaluation of colony growth and morphology

In this experiment six R. solani isolates were characterized as to their growth, color and sclerotia formation into three culture media, Nutrient Agar (NA)(Himedia(B), Potato Dextrose Agar (PDA) (Kasvi®) and Potato Sucrose Agar (PSA) (200 g potato, 20g sucrose, 20g agar, and $1000 \mathrm{ml}$ water). All media had $\mathrm{pH}$ adjusted to 7.0 with $0.5 \mathrm{M}$ sodium hydroxide or $0.2 \mathrm{M}$ hydrochloric acid and then taken to the autoclave $\left(120^{\circ} \mathrm{C}, 15\right.$ min, $1 \mathrm{~atm})$. After sterilization, $15 \mathrm{ml}$ of medium was added to each Petri dish of $9 \mathrm{~cm}$ diameter. The six isolates of the fungus were recorded, with a mycelial disc of $3 \mathrm{~mm}$ in diameter. The experiment was carried out in a $6 \times 3$ factorial scheme, with six isolates of the fungus and three different culture media, in a completely randomized design with 5 replicates per treatment. Each plot comprised one Petri dish.

Evaluations were done daily until the sixth day or until $90 \%$ of the plate were fully occupied by the fungus. The colony diameter was measured with the aid of a digital caliper. Fifteen days after the inoculation, the morphology of the colony of the fungus was described by color and shape of the mycelium, besides the formation of sclerodium on plate. It also calculated the indexes of mycelial growth rate (IMGR) using the expression by Pinto (2012): IMGR $=\sum$ (Dc-Dp)/N, where Dc is average of current colony diameter, Dp is average of previous colony diameter and $N$ is number of days after inoculation

Vegetative compatibility and anastomosis between isolates of $R$. solani

For this experiment the six isolates of $R$. solani were paired in all combinations. The pairing was mounted on petri dishes containing agar medium and $3 \mathrm{~mm}$ diameter mycelium discs which were peeled into the Petri dish and separated by a distance of $3 \mathrm{~cm}$. After seven days, the pairing of the isolates was evaluated and the combinations were classified according to Macnish et al. (1997) into three categories: fused, tuff and incompatible. In the "fused" category the two cultures come together with little or no evidence of demarcation; in the tuff category there is an area of distinct demarcation between the colonies that are occupied by a band of hyphae raised above the general level of the mycelium on the surface of Agar. The category "incompatible" is a category used to group the reactions that do not fit into the other categories and the junction of the hyphae does not occur. This experiment was set up in a completely randomized design with three replicates and fungi growth occurred at a temperature of $28^{\circ} \mathrm{C}$.

For the evaluation of the anastomosis between the isolates experiment was conducted in Petri dishes with PDA medium. The plates assembly scheme followed the vegetative compatibility, however, a sterilized cover slip was added between the mycelium disks of the isolates, where the hyphae grew and occasionally the anastomoses occurred, it was possible to observe the reaction of the hyphal fusion. This experiment was performed in a completely randomized design with two replicates and the growth of isolates occurred at temperature of $28^{\circ} \mathrm{C}$. To observe the hyphal fusion the cover slips were removed and the hyphal stained with Safranine O. Observations of microscopic structures were performed with the aid of an optical microscope (Nikon Eclipse E200 $(\circledR)$. The evaluation occurred with the detection or not of the anastomosis between the hyphae of different isolates, classified as absent or present. Statistical analysis

The scores obtained in the aggressiveness experiment and the IMGR were submitted to the normality test of the Shapiro-Wilk errors at $5 \%$ and after verifying the normality the data was performed the analysis of variance. The means of aggressiveness were submitted to Duncan's mean clustering test and IMGR to Scott-Knott both at $5 \%$ significance using the $\mathrm{R}$ Core Team program.

\section{Results and Discussion}

Isolates CMM1053 and CMM1052 were the most aggressive, with the mean scores of 4 and 3.8 respectively, however were not statistically different from CMM2983, CMM2971 CMM3890. CMM2967 was considered the less 
aggressive with a mean score of 2.8 (Table 2). Thus, knowledge of different levels of aggressiveness is of great interest in plant breeding work, since, susceptible varieties when inoculated with little aggressive isolated may show as resistant. On the other hand, when inoculated with very aggressive isolates, they may be highly susceptible (Van
Der Plank, 1968). The isolate CMM1053 in a study with Fava bean was considered one of the most aggressive, which was also observed in our study (Assunção, 2011). Plant samples with symptoms were taken to the laboratory for reisolation to prove the tissues were infected by the fungus.

Table 2. Mean score and standard deviation of the watermelon seedlings inoculated with the six isolates. Means followed by same letter do not differ statistically by mean Duncan test at $5 \%$ probability

\begin{tabular}{cc}
\hline Isolate & Mean score \pm Standard deviation \\
\hline CMM1053 & $4.0 \pm 0.00 \mathrm{a}$ \\
CMM1052 & $3.8 \pm 0.45 \mathrm{a}$ \\
CMM2983 & $3.6 \pm 0.55 \mathrm{ab}$ \\
CMM2971 & $3.4 \pm 0.55 \mathrm{ab}$ \\
CMM3890 & $3.2 \pm 1.10 \mathrm{ab}$ \\
CMM2967 & $2.8 \pm 0.84 \mathrm{~b}$ \\
Control & $0.0 \pm 0.00 \mathrm{c}$ \\
\hline
\end{tabular}

There was significant interaction between culture media and isolates for indexes of mycelial growth rate (IMGR) (Figure 1). The PSA medium was the one that obtained the highest IMGR, indicating that the majority of the isolates had the most accelerated growth in this medium. Isolates that had better growth in PSA medium were CMM2967 and CMM2971, with

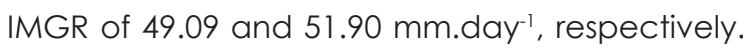
For the PDA medium the highest IMGR were from CMM1053, CMM3890, CMM2971 and CMM2967 isolates, ranging from 42.20 to 43.88. Agar nutrient medium was the one that had the lowest rates of growth speed. The isolates that had the highest IMGR were CMM1053, CMM2971, CMM2967 and
CMM3890, ranging from 39.30 to $45.51 \mathrm{~mm}$.day ${ }^{-1}$. These results show that depending on the culture medium, the isolates may behave differently, corroborating the results of MacNish et al. (1997), that found a difference in mycelial growth of Rhizoctonia solani isolates in PDA that belonging to the AG-10 anastomosis group. Most of the studies use PDA medium to evaluate the mycelial growth and the temperature of $25^{\circ} \mathrm{C}$ for growth is considered optimal (Erper et al., 2016; SilvaBarreto et al., 2010; Yang et al., 2015). Therefore, according to our results the PSA medium can also be included as an excellent medium for the growth of Rhizoctonia solani.

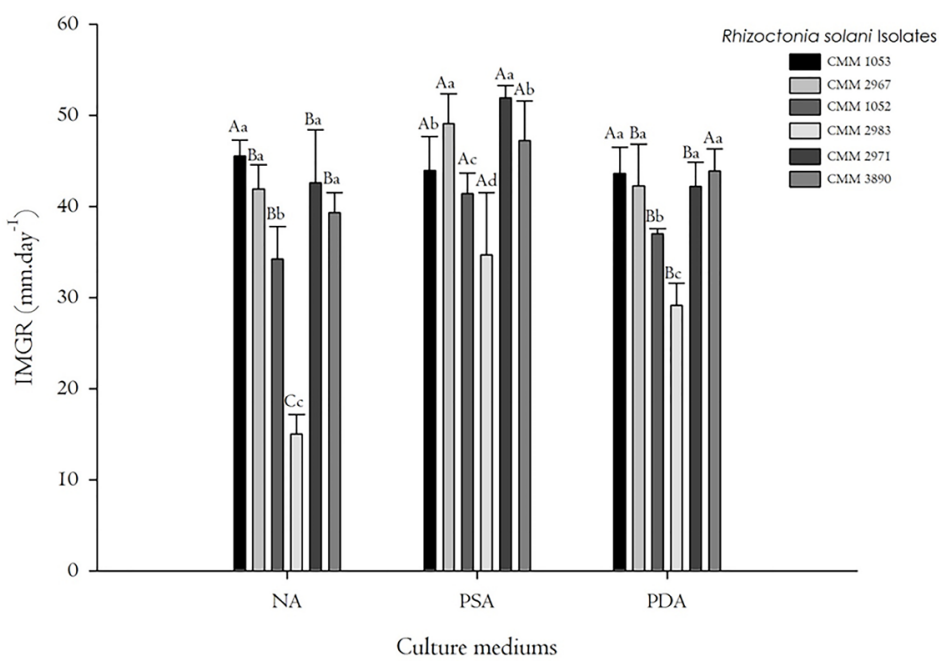

Figure 1. Indexes of mycelial growth rate (IMGR) (mm.day-1) from different isolates and culture medium (NA - Nutrient Agar, PSA - Potato Sucrose Agar and PDA - Potato Dextrose Agar). Means followed by the same lowercase letters among isolates and uppercase letters among culture medium, do not statistically differ by Scott-Knott test at 5\% significance 
Fifteen days-old cultures were evaluated for sclerotia formation, however sclerotia were not observed to any isolate used for all media tested. It was observed that there were differences in colony color depending on the medium, wherein the isolate CMM1053, CMM2983 and CMM1052 have a white colored colony on PDA and PSA media and the other isolates showed a brown color (Figure 2). It is also possible to emphasize that in the medium Nutrient Agar the fungi presented a brown darker color different from the color of the colony when grown in PDA or PSA. Erper et al. (2016) analyzing morphological characteristics of Rhizoctonia solani isolates belonging to the AG-4 anastomosis group found differences in both, colony color and sclerotia formation in PDA medium. We also observed color variability in our study as also observed by Sanfuentes et al. (2007). Spedaletti et al. (2016) showed that $62.9 \%$ of the colonies of Rhizoctonia solani grown in PDA had a light brown coloration and that only $20.6 \%$ had a white color. However, it was not found in the literature, the use of NA and PSA to observe colony color and growth. PSA was described to preservation of isolates (Zhang et al., 2016).

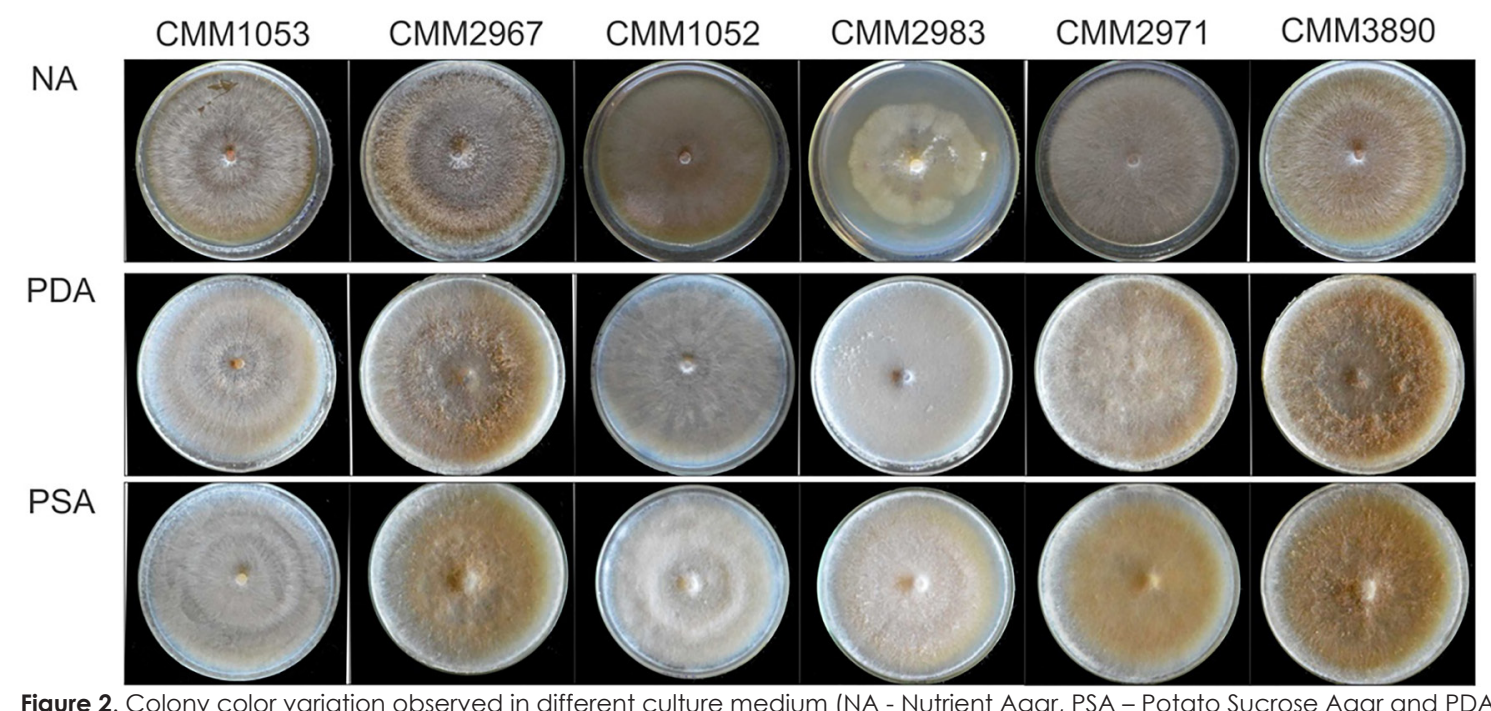

Figure 2. Colony color variation observed in different culture medium (NA - Nutrient Agar, PSA - Potato Sucrose Agar and PDA - Potato Dextrose Agar)

For vegetative compatibility only the combinations CMM1053 with CMM1052 and CMM2967 with CMM3890 were incompatible, that is, the hyphae did not arrive at any time close to each other. For most combinations the classification was as "fused", that is, the hyphae of the isolates overlapped one on top of the other (Table 3). The category "Tuff" was not observed in our experiment.

Table 3. Vegetative compatibility between Rhizoctonia solani isolates

\begin{tabular}{lllllll}
\hline Isolates & CMM1053 & CMM2967 & CMM1052 & CMM2983 & CMM2971 & CMM3890 \\
\hline CMM1053 & $\mathrm{x}^{* *}$ & $\mathrm{~F}^{*}$ & $\mathrm{I}$ & $\mathrm{F}$ & $\mathrm{F}$ & $\mathrm{F}$ \\
CMM2967 & & $\mathrm{X}$ & $\mathrm{F}$ & $\mathrm{F}$ & $\mathrm{F}$ & $\mathrm{I}$ \\
CMM1052 & & & $\mathrm{X}$ & $\mathrm{F}$ & $\mathrm{F}$ & $\mathrm{F}$ \\
CMM2983 & & & & $\mathrm{X}$ & $\mathrm{F}$ & $\mathrm{F}$ \\
CMM2971 & & & & & $\mathrm{x}$ & $\mathrm{F}$ \\
CMM3890 & & & & & $\mathrm{x}$ \\
*Vegetative compatibility between isolates. $\mathrm{F}=$ fused, I= incompatible and T= tuff. ** $\mathrm{x}=$ Pairing did not realized.
\end{tabular}

For the anastomosis of hyphae we can observe that all pairs were vegetatively compatible (Table 4). We can observe in detail the fusion of hyphae between isolates CMM1053 and CMM2967 (Figure 3A) and between isolates CMM2983 and CMM3890 (Figure 3B).
For most combinations it was possible to detect the presence of anastomosis, so we can infer that these isolates belong to the same anastomosis group. On the other hand, those combinations that did not present anastomoses were the same ones in which the vegetative 
Table 4. Hyphal anastomosis between Rhizoctonia solani isolates

\begin{tabular}{|c|c|c|c|c|c|c|}
\hline Isolates & CMM1053 & CMM2967 & CMM1052 & CMM2983 & CMM2971 & CMM3890 \\
\hline CMM1053 & $\mathrm{x}^{* *}$ & $\mathrm{~F}^{*}$ & $A$ & $P$ & $P$ & $P$ \\
\hline CMM2967 & & $x$ & $P$ & P & $P$ & A \\
\hline СMM1052 & & & $x$ & $P$ & $P$ & $P$ \\
\hline CMM2983 & & & & $x$ & $P$ & $P$ \\
\hline CMM2971 & & & & & $x$ & $P$ \\
\hline CMM3890 & & & & & & $x$ \\
\hline
\end{tabular}

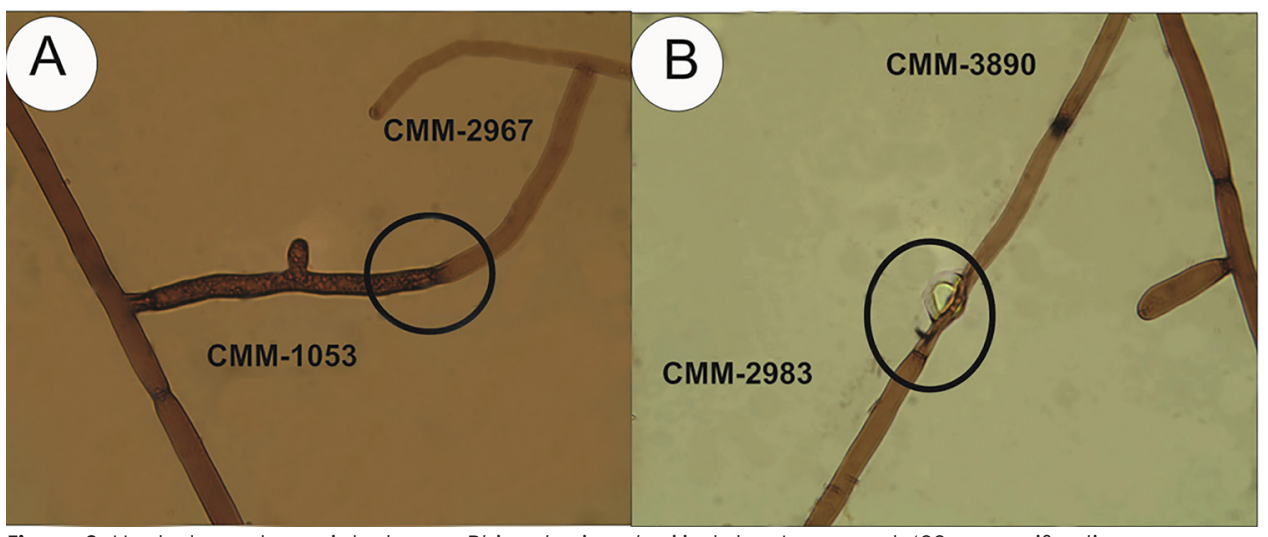

Figure 3. Hyphal anastomosis between Rhizoctonia solani isolates. Images at 400x magnification

compatibility was not observed. However in our study it was not possible to make the classification made by Sneh et al. (1996) based on the stability of the anastomosis, in which it classifies the perfect fusion as one in which the hyphae cell does not die after fusion. Hyphal fusion is a classical method widely used for identification and classification of Anastomosis groups (AG) among Rhizoctonia solani isolates and some groups have been subdivided into subgroups according to physiological differences and host specificity (Skonieczek et al., 2016; Yang et al., 2015). The fact that anastomosis occurs for most isolates may explain the fact that all isolates cause disease in watermelon. In order to determine which anastomosis group belongs, it is necessary that $R$. solani isolate be identified as belonging to identified group and them pairing with the other isolates or use of molecular methods with specific primers to determine the anastomosis group (Erper et al., 2016 Yang et al., 2017, Yang et al., 2015).

Thus, we identified variability for all traits evaluated and found an alternative medium (PSA) for fast growth of isolates. These results allowed us to identify the most aggressive strains to be used in the evaluation of resistance and will facilitate the work of breeders and pathologist working with damping-off of watermelon.

\section{Conclusions}

Variation was observed for all evaluated characters. The CMM1052 and CMM1053 isolates were the most aggressive, however they differed statistically only from the CMM2967 isolate, which was the least aggressive. The PSA medium was shown to be the most suitable for the rapid growth of the isolates of $R$. solani, being an alternative to the PDA for studies with $R$. solani. The isolates grown in nutrient agar had the highest color variation of the colony. By the hyphal anastomosis tests and vegetative compatibility the isolates belong to the same anastomosis group.

\section{References}

Aiello, D., Vitale, A., Hyakumachi, M., Polizzi, G. 2012. Molecular characterization and pathogenicity of binucleate Rhizoctonia AG-F associated to the watermelon vine decline in Italy. European Journal of Plant Pathology 134: 161- 165.

Assunção, I. P., Nascimento, L. D., Ferreira, M. F., Oliveira, F. J., Michereff, S. J., Lima, G. S. 2011. Reaction of faba bean genotypes to Rhizoctonia solani and resistance stability. Horticultura Brasileira 29: 492- 497.

Das, S., Shah, F. A., Butler, R. C., Falloon, R. E., Stewart, A., Raikar, S., Pitman, A. R. 2014. Genetic 
variability and pathogenicity of Rhizoctonia solani associated with black scurf of potato in New Zealand. Plant pathology 63: 651- 666.

Erper, I., Kilicoglu, M. C., Turkkan, M., Onder, H. 2016. Characterization and pathogenicity of Rhizoctonia spp. isolated from winter squash in the Black Sea region of Turkey. European Journal of Plant Pathology 146: 683- 697.

FAO. Food and Agriculture Organization of the United Nations. 2015. http://www.fao. org/<access on 20 aprl. 2017>

Fiers, M., Edel-Hermann, V., Héraud, C., Gautheron, N., Chatot, C., Hingrat, Y. L., Boucheck-Mechiche, K., Steinberg, C. 2011. Genetic diversity of Rhizoctonia solani associated with potato tubers in France. Mycologia 103: $1230-1244$.

Lakshman, D. K., Natarajan, S. S., Lakshman, S., Garrett, W. M., Dhar, A. K. 2008. Optimized protein extraction methods for proteomic analysis of Rhizoctonia solani. Mycologia 100: 867- 875.

Macnish, G. C., Carling, D. E., Brainard, K. A. 1997. Relationship of microscopic and macroscopic vegetative reactions in Rhizoctonia solani and the occurrence of vegetatively compatible populations (VCPs) in AG-8. Mycological Research 101: 61- 68.

Mathew, F. M., Lamppa, R. S., Chittem, K., Chang Y. W., Botschner, M., Kinzer, K., Markell, S. G. 2012. Characterization and pathogenicity of Rhizoctonia solani isolates affecting Pisum sativum in North Dakota. Plant disease 96: 666672.

Mikhail, M. S., Sabet, K. K., Omar, M. R., Asran, A. A., Kasem, K. K. 2010. Current Rhizoctonia solani anastomosis groups in Egypt and their pathogenic relation to cotton seedlings. African Journal of Microbiology Research 4: 386- 395.

Mirmajlessi, S. M., Safaie, N., Mostafavi, H. A. Mansouripour, S. M., Mahmoudy, S. B. 2012. Genetic diversity among crown and root rot isolates of Rhizoctonia solani isolated from cucurbits using PCR-based techniques. African Journal of Agricultural Research 7: 583- 590.

Noronha, M. A., Michereff, S. J., Mariano, R. L. R. 1995. Efeito do tratamento de sementes de caupi com Bacillus subtilis no controle de Rhizoctonia solani. Fitopatologia Brasileira 20: 174- 178.

Oliveira, A. C., Souza, P. E., Pozza, E. A., Figueira, A. R., Avelar, G. D., Gomes, E. A., Monteiro, F. P. 2014. Caracterização morfológica, genética e patogenicidade de isolados de Rhizoctonia solani provenientes de algodoeiros no Brasil. Bioscience Journal 30: 512- 524.
Pinto, J. M. A., Pereira, R., Mota, S. F., Ishikawa, F. H., Souza, E. A. 2012. Investigating Phenotypic Variability in Colletotrichum lindemuthianum Populations. Phytopathology 102: 490 - 497.

Ritchie, F., Bain, R., Mcquilken, M. 2013. Survival of Sclerotia of Rhizoctonia solani AG3PT and Effect of Soil-Borne Inoculum Density on Disease Development on Potato. Journal of Phytopathology 161: 180- 189.

Sanfuentes, E., Alfenas, A. C., Maffia, L. A., Mafia, R. G. 2007. Caracterização de Isolados de Rhizoctonia spp. e Identificação de Novos Grupos de Anastomose em Jardim Clonal de Eucalipto. Fitopatologia Brasileira 32: 229- 236.

Skonieczek, P., Nowakowski, M., Piszcek, J., Zurek, M., Matyka, L. 2016. Influence of selected Rhizoctonia solani isolates on sugar beet seedlings. Journal of Plant Protection Research 56: $116-121$.

Sherwood, R. T. 1970. Physiology of Rhizoctonia solani. In: Parmeter, J. R. (ed.) Rhizoctonia solani, biology and pathology. California Press, Los Angeles, USA. p. 69-92.

Silva-Barreto, F. A. D., Pereira, W. V., Ciampi, M. B., Câmara, M. P. S., Ceresini, P. C. 2010. Associação de Rhizoctonia solani Grupo de Anastomose 4 (AG-4 HGl e HGIII) à espécies de plantas invasoras de área de cultivo de batata. Summa Phytopathologica 36, 145- 154.

Sneh, B., Jabaji-Hare, S., Neate., S. Dijst. 1996. Rhizoctonia species: taxonomy, molecular biology, ecology, pathology and disease control. Springer Netherlands, Noordwijkerhout, Netherlands. 578 p.

Spedaletti, Y., Aparicio, M., Cárdenas, G. M., Rodriguero, M., Taboada, G., Aban, C., Suhring, S., Vizgarra, O., Galván, M. 2016. Genetic Characterization and Pathogenicity of Rhizoctonia solani Associated with Common Bean Web Blight in the Main Bean Growing area of Argentina. Journal of Phytopathology 164: 1054- 1063.

Van Der Plank, J. E. 1968. Disease resistance in plants. Academic Press, New York, USA. 206 p.

Yang, S., Min, F., Wang, W., Wei, Q., Guo, M., Gao, Y., Dong, X., LU, D. 2017. Anastomosis Group and Pathogenicity of Rhizoctonia solani Associated with Stem Canker and Black Scurf of Potato in Heilongjiang Province of China. American Journal of Potato Research 94: 95- 104.

Yang, Y., Zhao, C., Guo, Z., Wu, X. 2015. Anastomosis group and pathogenicity of Rhizoctonia solani associated with stem canker and black scurf of potato in China. European Journal of Plant Pathology 143: 99- 111. 
Galvão et al. (2018) / Characterization, pathogenicity and ...

Zhang, X. Y., HuO, H. L., Xi, X. M., Liu, L. L., YU, Zhuo., Hao, J. J. 2016. Histological observation of potato in response to Rhizoctonia solani infection. European Journal of Plant Pathology 145: 289 303. 